\title{
RESENHA: "Crafting Policies to End Poverty in Latin America. The Quiet Transformation"
}

Informações editoriais:

Autora: Ana Lorena De La O

Editora: Cambridge University Press

Ano: 2015

ISBN 978-1316105528

DOI: $10.1017 / C B O 9781316105528$

Sergio Simoni Jr.

Universidade Federal do Rio Grande do Sul (UFRGS)

E-mail: sergiojr_ssj@yahoo.com.br

\section{Maria Clara Oliveira}

Universidade Federal do Rio Grande do Sul (UFRGS)

E-mail: mariaclara.g.oliveira@gmail.com

As políticas de transferência condicionada de renda (TCR) ganharam centralidade nos últimos anos na comunidade política e acadêmica. Estes programas, presentes em quase toda a América Latina, consistem de transferências de dinheiro dirigidas a famílias pobres, sendo exigido em troca o cumprimento de condicionalidades nas áreas de saúde e educação e, em alguns casos, nutrição.

No decorrer dos últimos anos, muitos são os trabalhos que versam sobre as TCR, centrando-se tanto em um programa específico quanto usando casos comparados, discutindo questões variadas, tais como os desenhos dos programas, os seus impactos para os beneficiários ou os potenciais impactos eleitorais, entre outros.

O livro de Ana de la O, "Crafting Policies to End Poverty in Latin America", traz um olhar comparativo e de longo-prazo sobre os programas latino-americanos, conjugando métodos quantitativos e qualitativos. O estudo é rico por dialogar com as principais literaturas da política comparada e por se valer de ferramentas metodológicas avançadas e diversificadas.

O trabalho é marcado por duas preocupações conectadas ainda que distintas. A primeira é entender quais são os gatilhos que levam à adoção destes programas e suas diferenças em termos de desenho e implementação. A criação de políticas sociais tem sido explorada por 
SIMONI JR., Sergio; OLIVEIRA, Maria Clara. Resenha: “Crafting Policies to End Poverty in Latin America. The Quiet Transformation".

vários autores, com alguns a enfatizar a importância de uma comunidade epistêmica de apoio à disseminação de diferentes modelos (Osorio Gonnet, 2018; Sugiyama, 2008) e outros que ressaltam a importância da democracia para a adoção de políticas públicas voltadas para os outsiders (Garay, 2010), entre outros. Ana de la $\mathrm{O}$ traz uma nova perspectiva ao colocar no centro a relação entre Executivo e Legislativo no processo de criação e formulação dos programas. Já a segunda preocupação é o possível uso clientelista dos programas por parte do governo, questão que também tem preocupado outros autores (p. ex. Hunter e Sugiyama, 2013), e o seu potencial para erradicação da pobreza.

A teoria proposta por De La O, elaborada do ponto de vista formal no capítulo 3, tem por base uma característica importante e discernível das TCR: contrariamente às políticas tradicionais de welfare, estes programas não tem status de um direito garantindo (entitlement). Logo, a manutenção dos programas dependeria da ratificação anual dos recursos orçamentários pelo Parlamento. As TCR surgem, de um modo geral, num contexto de crise econômica e social e são as relações estabelecidas entre Executivo e Legislativo que determinam o tipo de programa que será implementado. O Executivo, ao propor a política, deve levar em consideração a futura necessidade de confirmação do seu financiamento a cada ano. Isso implicaria, no argumento da autora, que Congressos cujo legislador mediano seja alinhado com o Presidente permitiriam TCR com desenhos frouxos e implementação precária, passível de interferência por parte do governo (como acontece com o Bono Juancito Pinto boliviano). Legislativos cujo eleitor mediano tenha posição diversa da do Executivo exigiriam do Presidente a proposição de uma política com critérios rígidos, insulada de manipulações com propósitos políticos (como no caso do México). O argumento de De La O é o de que o tipo de TCR adotado tem impacto nas possíveis relações clientelistas, no seu uso eleitoral e na manutenção e apoio popular à política social no longo-prazo.

Para mensurar o grau de rigidez das políticas de transferência, a autora formula no capítulo 2 um índice de desenho e outro de implementação das políticas, a partir de documentos oficiais e relatórios nacionais e internacionais. Ambos são constituídos por cinco tópicos: focalização; condicionalidade; recadastramento; transparência e monitoramento; e avaliação. Para cada tópico, De La O avalia os programas de forma dicotômica, de modo que é atribuído 1

Revista Brasileira de Políticas Públicas e Internacionais, v.4, n.1, julho/2019, pp. 238-243. 
SIMONI JR., Sergio; OLIVEIRA, Maria Clara. Resenha: “Crafting Policies to End Poverty in Latin America. The Quiet Transformation".

caso a TCR alcance determinado quesito, e 0 caso contrário. O indicador final consiste na soma dos cincos tópicos.

Nos capítulos 4 e 5, De La O apresenta os testes principais de seu modelo teórico. Nas primeiras análises, os índices de desenho e de implementação são as variáveis dependentes. Diferentes modelos e especificações confirmam o efeito esperado: governos minoritários tendem a adotar políticas com desenho e implementação mais robusta. Essas evidências são complementadas com análise qualitativa de debates parlamentares de alguns casos (México, Colômbia, Peru, Guatemala e Argentina). Em outro momento da análise, De La O mostra que governos minoritários também tendem a não aumentar número de beneficiários em ano eleitoral e a formular programas mais longevos.

O programa mexicano Progresa/Oportunidades (PO) é objeto de um exame detalhado, sendo-lhe dedicada uma parte considerável do livro, os capítulos 6 e 7. Por meio de análise de survey e de experimentos de lista, De La O mostra que beneficiários do PO relatam menor participação e conhecimento de práticas clientelistas. Além disso, aproveitando-se do fato de que o programa foi implementado incialmente de forma experimental, a autora apresenta resultados eleitorais agregados que indicam que o programa implicou no aumento do comparecimento e no voto do incumbente, mas sem efeito negativo no voto na oposição, o que indicaria mecanismo de mobilização.

A análise do trabalho suscita algumas questões, que levantamos em seguida ${ }^{1}$. Primeiro, central na teoria da autora é a exigência da negociação anual no Congresso em torno do orçamento atribuído a cada programa. No entanto, alguns programas contam com financiamentos importantes provenientes de organismos regionais e/ou insituições financeiras internacionais (tais como o Banco Mundial e o Banco Interamericano de Desenvolvimento). Estes financiamentos podem ocorrer desde cedo, partir do momento de formulação do programa (Osorio Gonnet [2018: 136-137], identifica 12 países latinoamericanos nesta categoria), ou mais tarde, no momento da implementação, podendo minimizar a importância da relação Executivo-Legislativo. Logo, uma das questões que levantamos é: em que medida os

\footnotetext{
${ }^{1}$ Imai et al. (2019) elaboram críticas, aqui não tratadas, acerca dos procedimentos no tratamento dos dados na análise sobre efeito eleitoral do programa mexicano.
}

Revista Brasileira de Políticas Públicas e Internacionais, v.4, n.1, julho/2019, pp. 238-243. 
SIMONI JR., Sergio; OLIVEIRA, Maria Clara. Resenha: “Crafting Policies to End Poverty in Latin America. The Quiet Transformation".

resultados seriam alterados se fossem incorporados os fundos de fora do governo no desenho e na implementação das políticas?

Uma outra questão diz respeito à influência de atores externos ao governo. É sabido que atores para além do Executivo e Legislativo, como representantes de organizações não governamentais, acadêmicos e representantes de organizações internaconais têm, com frequência, integrado os grupos a cargo da formulação dos programas (Osorio Gonnet, 2018; Oliveira, 2018). Assim, perguntamo-nos de que modo uma maior ou menor presença desses atores externos ao governo pode diminuir o impacto das relações estabelecidas entre o Executivo e o Legislativo no desenho final, mais ou menos rígido, do programa.

Um terceiro ponto diz respeito aos indicadores de desenho e implementação. De fato, a proposta da autora tem muitos méritos, pois é abrangente e incorpora estratégias para minimizar viés advindo de auto-declaração dos governos. No entanto, uma técnica de somatório simples para formação de indicadores tem como pressuposto linearidade e igual importância de cada um dos componentes (Fortin, 2013). Isso pode não ser o caso. Os programas variam no que diz aos seus objetivos. Alguns consideram prioritário o alcance dos mais pobres, outros ressaltam a importância do constante e adequado recadastramento ${ }^{2}$. Dessa forma, seria possivelmente adequado realizar outras técnicas de formação de índices, como análise fatorial, por exemplo.

Um quarto ponto crítico que queremos chamar atenção diz respeito à mensuração da variável explicativa de interesse. Não é claro se a autora considerou tamanho da coalizão ou tamanho do partido do Presidente. Como se sabe, a existência de coalizões é difundida na América Latina (Chasquetti, 2011; Figueiredo et. al., 2012) e De La O não é clara neste ponto, o que pode enviesar a análise realizada. Por fim, como análises mais detidas foram feitas unicamente para o caso mexicano, o trabalho não oferece um contrafactual sobre efeito eleitoral e nas práticas clientelistas dos casos com TCR de precário desenho e implementação.

Reconhecendo a importância das contribuições da autora para o debate, consideramos que seriam bem-vindos estudos que repliquem o modelo proposto pela autora a outros casos, com o intuito de testar a sua validade. Por exemplo, o caso brasileiro é amplamente estudado na

\footnotetext{
${ }^{2}$ Para um panorama geral sobre os programas de TCR na América Latina, ver Cecchini e Madariaga (2011).
}

Revista Brasileira de Políticas Públicas e Internacionais, v.4, n.1, julho/2019, pp. 238-243. 
SIMONI JR., Sergio; OLIVEIRA, Maria Clara. Resenha: "Crafting Policies to End Poverty in Latin America. The Quiet Transformation".

literatura, tanto no debate sobre clientelismo (Hunter e Sugiyama, 2013); sobre retorno eleitoral (Zucco, 2008; Zucco e Power, 2013; Bohn, 2011; Simoni Jr, 2017) e sobre importância das ideias na formatação e desenho do programa (Oliveira, 2018; Monteiro, 2011). No entanto, pouco se avançou na análise sobre os processos de deliberação entre Executivo e Legislativo na formulação do Bolsa Família, política capitaneada pelo Partido dos Trabalhadores (PT), ainda mais se lembrarmos que se tratava de unificação de programas sociais prévios, formulados pelo Partido da Social Democracia Brasileira (PSDB).

Em suma, o excelente livro "Crafting Policies to End Poverty in Latin America" não apenas apresenta contribuições e inovações importantes como incentiva novas agendas de pesquisa.

\section{Referências}

Bohn, S. (2011). Social policy and vote in Brazil. Latin American Research Review, 46 (1).

Cecchini, S., \& Madariaga, A. (2011). Programas de Transferencias Condicionadas. Balance de la experiencia reciente en América Latina y el Caribe. Santiago de Chile: CEPAL.

Chasquetti, D. (2011). Democracia, Multipartidarismo y coaliciones en America Latina: evaluando la difícil combinación. In: Lanzaro, J.; \& Novaro, M. Tipos de presidencialismo y coaliciones políticas en America Latina. Buenos Aires: CLACSO.

Figueiredo, A.; Canello, J.; \& Vieira, M. (2012) Governos minoritários no presidencialismo latino-americano: determinantes institucionais e políticos. Dados [online], 55 (4), 839-875.

Fortin, J. (2013) Measuring presidential powers: Some pitfalls of aggregate measurement. International Political Science Review. 34 (1), 91 - 112.

Garay, C. M. (2010) Including outsiders: Social Policy Expansion in Latin America (Tese de Doutorado). Ciência Política. Universidade da California, Berkeley, California, Estados Unidos da América.

Hunter, W., \& Sugiyama, N. B. (2013, outubro) Whither clientelism? Good governance and Brazil's Bolsa Família Program. Comparative Politics, 43-62.

Revista Brasileira de Políticas Públicas e Internacionais, v.4, n.1, julho/2019, pp. 238-243. 
SIMONI JR., Sergio; OLIVEIRA, Maria Clara. Resenha: “Crafting Policies to End Poverty in Latin America. The Quiet Transformation".

Imai, K.; \& King, G.; \& Rivera, C. V. (2019). Do Nonpartisan Programmatic Policies Have Partisan Electoral Effects? Evidence from Two Large Scale Experiments. Journal of Politics, $81(2)$.

Monteiro, I. (2011) Integração de políticas sociais: um estudo de caso sobre o Bolsa Família (Dissertação de Mestrado). Bens Culturais e Projetos Sociais, Centro de Pesquisa e Documentação de História Contemporânea do Brasil, Fundação Getúlio Vargas, Rio de Janeiro, RJ, Brasil.

Oliveira, M. C. (2018) Ideias e políticas públicas. Considerações a partir da análise de programas de transferência monetária na África do Sul, no Brasil e no Chile (Tese de Doutorado). Ciência Política, Universidade de São Paulo, São Paulo, SP, Brasil.

Osorio Gonnet, C. (2018) Aprendiendo o emulando? Cómo se difunden las políticas sociales en América Latina. Santiago de Chile: LOM Ediciones.

Simoni Jr, S. (2017) Política distributiva e competição presidencial no Brasil: Programa Bolsa-Família e a tese do realinhamento eleitoral (Tese de Doutorado). Ciência Política, Universidade de São Paulo, São Paulo, SP, Brasil.

Sugiyama, N. B. (2011) The diffusion of conditional cash transfer programs in the Americas. Global Social Policy. https://doi.org/10.1177/1468018111421295

in Brazil. LARR, 43 (3), 82-108.

(2008) Ideology and networks. The politics of social policy diffusion

Zucco, C. (2008). The President's 'New' Constituency: Lula and the Pragmatic Vote in Brazil's 2006 Presidential Election. Journal of Latin American Studies, 40 (1).

Zucco, C.; \& Power, T. (2013). Bolsa-Família and the Shift in Lula's Electoral Base, 20022006. Latin American Research Review, 48 (2).

Revista Brasileira de Políticas Públicas e Internacionais, v.4, n.1, julho/2019, pp. 238-243. 